\title{
Comparison of Sonography and MRI in Diagnosis of Rotator Cuff Injuries
}

\author{
Sied Kazem Razavi Ratki ${ }^{1}$, Masoud Nakhaie-Nejad ${ }^{2}$, Nasim Namiranian ${ }^{3}$, \\ Hamid reza Shafai Arani ${ }^{1}$, Mona Ghasemian ${ }^{2}$, Reza Nafisi-Moghadam ${ }^{1, *}$ \\ ${ }^{1}$ Department of Radiology, Faculty of Medicine, Shahid Sadoughi University of Medical Sciences, Yazd, Iran \\ ${ }^{2}$ Faculty of Pharmacy, Shahid Sadoughi University of Medical Sciences, Yazd, Iran \\ ${ }^{3}$ Yazd Diabetes Research Center, Shahid Sadoughi University of Medical Sciences, Yazd, Iran \\ Email address: \\ nafisi@ssu.ac.ir (R. Nafisi-Moghadam)
}

\section{To cite this article:}

Sied Kazem Razavi Ratki, Masoud Nakhaie-Nejad, Nasim Namiranian, Hamid reza Shafai Arani, Mona Ghasemian, Reza Nafisi-Moghadam. Comparison of Sonography and MRI in Diagnosis of Rotator Cuff Injuries. International Journal of Clinical and Experimental Medical Sciences. Vol. 1, No. 3, 2015, pp. 35-37. doi: 10.11648/j.ijcems.20150103.11

\begin{abstract}
Background and Objectives: Rotator cuff injuries are problems commonly encountered in athletic and non-athletic patients. Its definite diagnosis is also important. Accordingly, this study was performed to determine the diagnostic accuracy of ultra-sonography (US) compared with magnetic resonance imaging (MRI) in cases with suspicion of rotator cuff injuries. Methods and materials: In this prospective comparative study, 130 patients who had undergone shoulder arthroscopy and open rotator cuff repairing and confirm rotator cuff tears have been enrolled and evaluated with both ultrasonography and MRI methods. Results: The overall sensitivity ( $95 \%$ confidence interval[CI]) of US was $87.64 \%$ (78.55-93.37), the specificity $(95 \% \mathrm{CI})$ was $89.02 \%$ (61.24-95.45). The overall sensitivity (95\% confidence interval) of MRI was $91.31 \%(75.47-94.4)$ and the specificity $(95 \% \mathrm{CI})$ of MRI was $83.02 \%(61.23-91.45)$. There was no statistical significance between sensitivity of two methods (p-value: 0.092). Conclusions: Totally, according to our findings and comparison with other similar studies, it could be concluded that ultrasonography has a good diagnostic modality in patients suspicious to rotator cuff tearing compared with MRI as a more diagnostic imaging test. Accordingly, its use is recommended in patients suspicious to have rotator cuff tearing.
\end{abstract}

Keywords: Rotator Cuff Tearing, Ultrasonography, MRI

\section{Introduction}

Rotator cuff injuries are problems commonly encountered in athletic and nonathletic patients. Those symptoms include pain, weakness, and limitation of motion. Early diagnosis is important for identifying causes, implementing effective treatment, and preventing further injury. ${ }^{1}$

Shoulder sonography is a valuable method of evaluating the rotator cuff..$^{2}$ In experienced hands, it is as sensitive as arthrography and magnetic resonance imaging for detecting rotator cuff tears and abnormalities of the biceps tendon., ${ }^{3,4}$ Because sonography is rapid, noninvasive, relatively inexpensive, and capable of performing bilateral examinations in one sitting, it should be used as the initial imaging test when the primary question is one of rotator cuff abnormalities. ${ }^{2,5,6}$ Accordingly, this study was performed to determine the diagnostic accuracy of sonography compared with MRI in cases with suspicion of rotator cuff injuries.

\section{Methods \& Materials}

The current study was performed as a comparative crosssectional study. In this study, 130 patients suspicious to rotator cuff tears have been evaluated with both ultrasonography and MRI methods. The study was performed in Shahid Sadoughi hospital of Shahid Sadoughi university of Medical sciences in Yazd during winter-spring of 2011.

MRI was performed with 1.5 Tesla Siemens machine and Sonography with 10-13 transducers (Siemens) with two separate radiologists.

All the rotator cuff muscles were determined with MRI and Sonography for full-thickness and partial tearing. Finally, we performed data analysis by SPSS-13 statistical software. The sensitivity and specificity of US compared with MRI were calculated. Comparison between two methods was done by McNemar Chi-Square test. 


\section{Results}

Totally 130 patients suspicious with rotator cuff tears have been studied. The mean age of patients was $43.2 \pm 7.1$ years old. Most of the patients (59.23\%) were women. Eighty nine patients $(68.5 \%)$ had positive US results. All the cases with full-thickness tearing, according to MRI were determined in the US. Among the nine patients with full-thickness supraspinatus tearing, eight cases had partial-thickness subscapularis tearing and seven cases had partial-thickness infraspinatus tearing. No case of tearing was observed in Teres minor muscle. About $72.3 \%$ had positive MRI results that among these 94 patients, 85 subjects had partialthickness supraspinatus tearing and nine had full-thickness supraspinatus tearing. These nine patients with full-thickness supraspinatus tearing had partial-thickness subscapularis tearing and nine had partial-thickness infraspinatus tearing. No case of tearing has been observed in Teres minor muscle.

The overall sensitivity (95\% confidence interval) of US was $87.64 \%$ (78.55-93.37), the specificity (95\%CI) was $89.02 \% \quad(61.24-95.45)$. The overall sensitivity (95\% confidence interval) of MRI was $91.31 \%$ (75.47-94.4) and the specificity $(95 \% \mathrm{CI})$ of MRI was $83.02 \%(61.23-91.45)$. There was no statistical significance between sensitivity of two methods (p-value: 0.092).

Table 1. Comparison of US and MRI results among patients.

\begin{tabular}{llll}
\hline & Positive MRI & Negative MRI & Total \\
\hline Positive US & $86(66.1 \%)$ & $3(2.3 \%)$ & $89(68 \%)$ \\
Negative US & $8(6.1 \%)$ & $33(25.39 \%)$ & $41(31.53 \%)$ \\
& $94(72.3 \%)$ & $36(27.7 \%)$ & $130(100 \%)$ \\
\hline
\end{tabular}

All patients with full-thickness supraspinatus in MRI were detectable by the US. The sensitivity of US was $100 \%$, the specificity was $100 \%$, Among 85 patients with partialthickness supraspinatus tearing in MRI 77 patient determined by US. The sensitivity of US was $90.6 \%$, the specificity was $100 \%$, the positive predictive value was $100 \%$, and the negative predictive value was $53 \%$. Among the nine patients with partial-thickness subscapularis tearing in MRI, eight were diagnosed by US. The sensitivity of US was $88.9 \%$, the specificity was $100 \%$, the positive predictive value was $100 \%$, and the negative predictive value was $98.7 \%$. Among the nine patients with partial-thickness infraspinatus tearing in MRI, seven were diagnosed by US. The sensitivity of US was $77.8 \%$, the specificity was $100 \%$, the positive predictive value was $100 \%$, and the negative predictive value was $97.5 \%$.

\section{Discussion}

Rotator cuff tear is a common injury of soft shoulder tissues. Ultrasonography and magnetic resonance imaging are often used to confirm an initial clinical diagnosis. Although a number of studies have focused on the sensitivity of ultrasonography and MRI to detect the presence or absence of partial or complete rotator cuff tears, only a few studies have directly compared these diagnostic methods. ${ }^{7}$

Several different imaging techniques are available for evaluating the rotator cuff and biceps tendon. The most common disorders of impingement, rotator cuff tears and biceps tendonitis are discussed along with the role which the various imaging modalities can play in establishing their diagnosis. Plain radiographs can be helpful, particularly with a history of trauma but give limited information on the soft tissues. Ultrasound is a useful and inexpensive method of assessing the rotator cuff and biceps tendon, but there are some limitations and various reports on its accuracy. Computed tomography (CT) is most helpful in evaluation of shoulder trauma, but gives limited information on the soft tissues. Magnetic resonance imaging (MRI) is an accurate imaging modality for evaluating the rotator cuff and biceps tendon, allowing visualization of the soft tissues and the adjacent bony structures. ${ }^{5}$ Dynamic shoulder ultrasonography is a noninvasive, accurate method used to assess the rotator cuff tendons. It can be incorporated into the in-office physical examination of patients at risk for rotator cuff problems. The low cost, convenience, and lack of risk turn dynamic ultrasonography into an excellent imaging tool for evaluating the biceps, subscapularis, infraspinatus, teres minor, and supraspinatus tendons. In-office ultrasound, also provides an opportunity for patient education and explanation of management options. ${ }^{8}$

In this study, $72.3 \%$ had positive MRI results that among these 94 patients, 85 subjects had partial-thickness supraspinatus tearing and nine had full-thickness supraspinatus tearing. These nine patients with full-thickness supraspinatus tearing had partial-thickness subscapularis tearing and nine had partial-thickness infraspinatus tearing. No case of tearing has been observed in Teres minor muscle. $68.5 \%$ had positive US results. All patients with fullthickness supraspinatus in MRI have been determined by the US. Among 85 patients with partial-thickness supraspinatus tearing in MRI 77 patient have been determined by the US. Among the nine patients with partial-thickness subscapularis tearing in MRI, eight cases have been diagnosed by US. Among the nine patients with partial-thickness infraspinatus tearing in MRI, seven cases have been diagnosed by US.

In a study has been carried out by Schibany et al, ${ }^{9}$ sonographic examinations of the shoulder of 212 asymptomatic individuals between 18 and 85 years old were performed by a single experienced operator. The prevalence and location of complete rotator cuff tears were evaluated. Ultrasound showed a complete rupture of the supraspinatus tendon in $6 \%$ of 212 patients from 56 to 83 years of age. MRI confirmed a complete rupture of the supraspinatus tendon in $90 \%$ that is near to $91.66 \%$ obtained in our study. All patients reported no functional deficits, although strength was significantly lower in the patient group with complete supraspinatus tendon tear.

The study, has been fulfilled by Teefey et al, ${ }^{10}$ demonstrated that US correctly identified all sixty-five fullthickness rotator cuff tears (a sensitivity of 100 percent). There were seventeen true-negative and three false-positive 
ultra-sonograms showing a specificity of 85 percent that is lower than our study.

Innaotti et $\mathrm{al}^{6}$ have demonstrated that office-based ultrasonography led to the correct diagnosis for thirty-seven $(88 \%)$ of forty-two shoulders with a full-thickness rotator cuff tears or both full and partial-thickness tears, twenty-six (70\%) of thirty-seven shoulders with a partial-thickness rotator cuff tear only, and sixteen (80\%) of twenty shoulders with normal tendons. However the sensitivity and specificity were higher in our study. In their study, there were no significant differences between magnetic resonance imaging and ultrasonography with regard to the correct identification of a full-thickness tear that is similar to our findings. Using ultrasound to visualize the shoulder area has advantages to other imaging techniques such as CT scans or MRI as it allows spatial examination during the motion of individual structures in the shoulder, and this technique is also relatively cheap and readily available. ${ }^{6}$ On the other hand, the ability of ultrasound waves to penetrate tissues is limited, and this technique requires very experienced examiners. Due to these limitations, the diagnosis of some conditions, such as labrum or capsular defects or damage to articular cartilage, is problematic. ${ }^{11}$ In the literature, ultrasound examination of rotator cuff tears has generally shown very high sensitivity $(75-100 \%)$ and specificity $(85-98 \%)$ that this matter is in congruence with our findings showing a sensitivity of $91.84 \%$ and specificity of $91.66 \%$. However, sensitivity has often been lower for partial tears or damage in the infraspinatus area. ${ }^{6,12-15}$

Another positive aspect of ultrasonography is the relatively small discomfort experienced by patients during the examination when compared with other techniques (level of discomfort was estimated based on patients' reports of pain intensity, duration and willingness to undergo a repeat examination).

\section{Conclusions}

Totally, according to our findings and comparison with other similar studies, it may be concluded that ultrasonography has a good diagnostic modality in patients suspicious to rotator cuff tears compared with MRI as a more diagnostic imaging test. Accordingly, using sonography is recommended in patients suspicious to rotator cuff tears.

\section{References}

[1] Dalton S. The conservative management of rotator cuff disorders. Br J Rheumatol. 1994;33:663-667.

[2] Teefey SA, Rubin DA, Middleton WD, Hildebolt CF, Leibold RA, Yamaguchi K. Comparison of ultrasonographic, magnetic resonance imaging, and arthroscopic findings in seventy-one consecutive cases. J Bone Joint Surg Am. 2004;86:708-716.
[3] Smith TO, Daniell H, Geere J-A, Toms AP, Hing CB. The diagnostic accuracy of MRI for the detection of partial-and full-thickness rotator cuff tears in adults. Magn Reson Imaging. 2012;30:336-346.

[4] Lenza M, Buchbinder R, Takwoingi Y, Johnston RV, Hanchard NC, Faloppa F. Magnetic resonance imaging, magnetic resonance arthrography and ultrasonography for assessing rotator cuff tears in people with shoulder pain for whom surgery is being considered. Cochrane Database Syst Rev. 2013; 9:CD009020.

[5] de Jesus JO, Parker L, Frangos AJ, Nazarian LN. Accuracy of MRI, MR arthrography, and ultrasound in the diagnosis of rotator cuff tears: a meta-analysis. AJR Am J Roentgenol. 2009;192:1701-1707.

[6] Iannotti JP, Ciccone J, Buss DD, et al. Accuracy of officebased ultrasonography of the shoulder for the diagnosis of rotator cuff tears. J Bone Joint Surg Am. 2005;87:1305-1311.

[7] Moosmayer S, Smith H-J, Tariq R, Larmo A. Prevalence and characteristics of asymptomatic tears of the rotator cuff AN ULTRASONOGRAPHIC AND CLINICAL STUDY. J Bone Joint Surg Br. 2009;91:196-200.

[8] Pujol N, Hargunani R, Gadikoppula S, Holloway B, Ahrens P.M. Dynamic ultrasound assessment in the diagnosis of intraarticular entrapment of the biceps tendon (hourglass biceps): A preliminary investigation. Int J Shoulder Surg. 2009;3:8084.

[9] Schibany N, Zehetgruber H, Kainberger F, et al. Rotator cuff tears in asymptomatic individuals: a clinical and ultrasonographic screening study. Eur J Radiol. 2004;51:263268.

[10] Teefey SA, Middleton WD, Yamaguchi K. Shoulder sonography. State of the art. Radiologic clinics of North America. 1999;37:767-785.

[11] Teefey SA, Hasan SA, Middleton WD, Patel M, Wright RW, Yamaguchi K. Ultrasonography of the rotator cuff. A comparison of ultrasonographic and arthroscopic findings in one hundred consecutive cases. J Bone Joint Surg Am. 2000;82:498-504.

[12] Seltzer SE, Finberg HJ, Weissman BN. Arthrosonography-technique, sonographic anatomy, and pathology. Invest Radiol. 1980;15:19-28.

[13] Crass JR, Craig EV, Bretzke C, Feinberg SB. Ultrasonography of the rotator cuff. Radiographics. 1985;5:941-953.

[14] Middleton WD, Reinus WR, Totty WG, Melson CL, Murphy WA. Ultrasonographic evaluation of the rotator cuff and biceps tendon. J Bone Joint Surg Am. 1986;68:440-450.

[15] Al-Shawi A, Badge R, Bunker T. The detection of full thickness rotator cuff tears using ultrasound. J Bone Joint Surg Br. 2008;90:889-892. 